The Society for Healthcare Epidemiology of America

\begin{tabular}{|c|c|c|c|}
\hline President & William J. Martone, MD/Bethesda, Maryland & TREASURER & Alan I. Hartstein, MD/Indianapolis, Indiana \\
\hline President-Elect & Robert A. Weinstein, MD/Chicago, Illinois & Councilor & John W. Froggatt, III, MD/Asheville, North Carolina \\
\hline Vice President & Elias Abrutyn, MD/Philadelphia, Pennsylvania & COUNCILOR & Edward S. Wong, MD/Richmond, Virginia \\
\hline Past President & Bryan P. Simmons, MD/Memphis, Tennessee & COUNCILOR & Barry M. Farr, MD, MSc/Charlottesville, Virginia \\
\hline SECRETARY & Lindsay E. Nicolle, MD/Winnipeg, Manitoba & COUNCILOR & Martha Tanner, MD/Idaho Falls, Idaho \\
\hline
\end{tabular}

\title{
SHEA Annual Meeting Opportunities
}

Preregistration closed in March for the sixth annual meeting, to be held in Washington, DC, April 21-23, 1996. Although record attendance is expected, on-site registration may be possible. If your schedule and budget will permit attendance, please call the SHEA meetings department, (609) $845-1720$, to ascertain availability for any of the four workshops on April 20, as well as for the annual meeting. Included with the 1996 SHEA dues statement was a request for you to express interest in participating in a SHEA committee. At the annual meeting, there will be a bulletin board sign-up opportunity where you may indicate interest in any of the standing or position paper committees (see the recently distributed 1996 Membership and Resource Directory, page 4).

The content for the $1997 \mathrm{sev}$ enth annual meeting program will be finalized in May 1996. Please forward suggestions to Leonard Mermel, Coordinator for the Scientific Program, or to Glen Mayhall, Chair of the Annual Meeting Planning Committee.

\section{Occasional Surveys: Varicella Immunization for Healthcare Workers in Acute-Care Facilities}

\begin{abstract}
As epidemiologists continue to see new patient exposure episodes involving healthcare workers with chickenpox, they must consider how they intend to use the new varicella vaccine. How SHEA members are organizing the deployment of a vaccine strategy in their organizations is queried in the following survey. The results of this survey will be published in a subsequent issue.
\end{abstract}

\section{Varicella susceptibility information \\ By means of :} is obtained on:

(1) Newly hired patient-care employees / _

(2) Current patient-care employees / _ /

(3) Medical staff /__

Varicella vaccine is offered to:

(1) Susceptible new hires / / /

(2) Susceptible current employees /__

(3) Susceptible medical staff / _ /

Cost of vaccine and its administration is assumed by:

(1) Individual immunized / _ /

(2) Healthcare organization /__
(1) History of chickenpox /__

(2) By serology /__

Susceptibility is confirmed by:

(1) History of chickenpox /__

(2) By serology /__

Nature of organization:

(1) Teaching: /__ $/ \mathrm{Y}$ ) or /__ $/ \mathrm{N}$

(2) Size: (average daily census):
(a.) $<100$ beds
(b.) $100-250$ beds
(c.) $251-400$ beds
(d.) $>401$ beds

(3) Finance:

(1) Privately owned

(2) Government owned

Organization's zipcode (to reduce duplication in tallying results). 